\title{
ESTUDO COMPARATIVO DO EFEITO DA PASSIVACC̃O QUÍMICA COM ÁCIDO SULFÚRICO E COM ÁCIDO NÍTRICO NO AÇO INOXIDÁVEL FERRÍTICO AISI 439
}

\author{
Leonardo F. Viezzer*, Mirela Di G. Bezerra, Isabella P. Santos
}

\begin{abstract}
Resumo
A pesquisa propôs uma avaliação do mais indicado entre dois métodos de passivação para o aço ferrítico AISI 439, em que, através da oxidação em solução de ácido sulfúrico e de ácido nítrico da superfície do metal, induziu-se a formação da camada passiva, que por sua vez foi imersa em concentrações progressivas de $\mathrm{HCl}$ para que se medisse sua resistência à corrosão por medidas de potencial de circuito aberto (Eca), com o uso de um eletrodo de referência (ECS).
\end{abstract}

\section{Palavras-chave:}

Passivação, decapagem, AISI 439.

\section{Introdução}

A corrosão pode ser definida como a deterioração de um material, geralmente metálico, por ação química ou eletroquímica do meio ambiente, aliada ou não a esforços mecânicos. ${ }^{1}$ Ligas de ferro-cromo apresentam a importante e desejada propriedade de elevada resistência à oxidação e corrosão: tal resistência é resultado do fenômeno conhecido como passivação², sendo definida como uma proteção formada na superfície do aço, insolúvel, estável e muito fina ${ }^{3}$. Apesar dessa camada passiva ser formada espontaneamente em aços inoxidáveis, sua formação pode ser acelerada e potencializada através de tratamentos químicos ${ }^{4}$. Para melhor eficiência da passivação é necessário submeter a superfície do metal a um pré-tratamento visando deixá-la uniforme e livre de impureza, a decapagem química. ${ }^{5} \mathrm{O}$ objetivo deste estudo é comparar as passivações em solução 0,5 mol.L-1 $\mathrm{H}_{2} \mathrm{SO}_{4}(15 \%)$ e em solução de $\mathrm{HNO}_{3}$ $(40 \%(v / v))$ no aço AISI 439 através de medidas de potencial de circuito aberto, encontrando o limite de resistência do AISI 439 em meios de ácido clorídrico.

\section{Resultados e Discussão}

Amostras do aço inoxidável ferrítico AISI 439 foram submetidas ao lixamento manual, sendo utilizadas lixas (320, 400 e 600 mesh), logo em seguida lavando-se as placas com água destilada e secando-as com ar quente; ambas as amostras foram decapadas em solução de Nital mistura 9:1 de álcool etílico P.A $+\mathrm{HNO}_{3}(40 \%(\mathrm{v} / \mathrm{v}))$ por um minuto. Passivaram-se as placas mergulhandose em solução de 0,5 mol. $\mathrm{L}^{-1} \mathrm{H}_{2} \mathrm{SO}_{4}$ (15\%) durante 30 minutos, a fim de se induzir a formação de uma camada passiva de óxido de crômio na superfície do aço; enxaguaram-se as amostras com água destilada e secou-se com ar quente. Cada amostra foi conectada a um eletrodo de referência de calomelano saturado (ECS) a fim de se medir a diferença de potencial, obtendo-se os potenciais de circuito aberto, sendo registrados os valores durante 60 minutos (potencial de corrosão Ecorr), imersas no meio corrosivo. Repetiu-se o procedimento anterior com o aço AISI 439, todavia mudando-se o passivante para $\mathrm{O}^{\mathrm{HNO}_{3}}(40 \%(\mathrm{v} / \mathrm{v}))$, obtendo-se seus valores de Ecorr, e os valores de Ecorr do aço somente na condição lixado + decapado ${ }^{6}$.

Foram obtidos os valores de Ecorr do aço somente lixado em meio de $\mathrm{HCl}$ ("branco") 7 , para efeito comparativo da camada passiva atuante, realizando-se todos os procedimentos de imersão em temperatura ambiente. Tabela 1. Potenciais de corrosão (mV/ECS)

\begin{tabular}{|c|c|c|c|c|c|}
\hline \multirow{2}{*}{\multicolumn{2}{|c|}{ AISI 439}} & \multirow{2}{*}{$\begin{array}{l}\text { BRANCO } \\
\text { DECAPADO }\end{array}$} & \multirow{2}{*}{$\begin{array}{l}\text { BRANCO } \\
\text { LIXADO }\end{array}$} & $\mathrm{HNO}_{3} 40 \%(\mathrm{v} / \mathrm{v})$ & $0,5 \mathrm{M} \mathrm{H}_{2} \mathrm{SO}_{4}(15 \%)$ \\
\hline & & & & \multicolumn{2}{|c|}{$30 \mathrm{~min}$ - passivação } \\
\hline \multirow{4}{*}{ 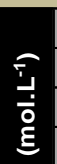 } & 0,10 & $-160 \pm 12^{*}$ & $-520 \pm 5^{*}$ & $-129 \pm 10^{*}$ & $-108 \pm 3$ \\
\hline & 0,30 & $-144 \pm 8^{*}$ & $-503 \pm 2^{*}$ & $-32 \pm 11^{*}$ & $-103 \pm 4$ \\
\hline & 0,50 & $-154 \pm 9^{*}$ & $-484 \pm 1^{*}$ & $-3 \pm 1^{*}$ & $-63 \pm 10$ \\
\hline & 0,70 & $-469 \pm 4^{*}$ & $-475 \pm 1^{*}$ & $+11 \pm 31^{*}$ & $-107 \pm 4$ \\
\hline \multirow{3}{*}{$\overline{\mathrm{O}}$} & 0,90 & $-463 \pm 1^{*}$ & $-475 \pm 1^{*}$ & $+40 \pm 0^{*}$ & $-127 \pm 17$ \\
\hline & 1,00 & - & $-471 \pm 2^{*}$ & $+19 \pm 2^{*}$ & $-89 \pm 11$ \\
\hline & 1,20 & - & - & - & $-456,5 \pm 4,5$ \\
\hline
\end{tabular}

Gráfico 1. Comparativo gráfico no meio agressivo de $\mathrm{HCl}$.

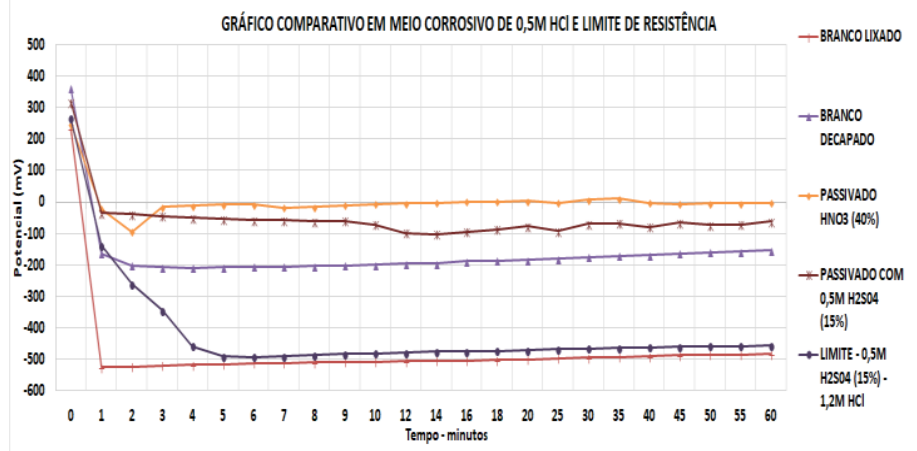

\section{Conclusões}

A passivação com $\mathrm{HNO}_{3}$ é mais eficiente na proteção a corrosão, em concentrações acima de 0,10 mol. $\mathrm{L}^{-1} \mathrm{HCl}$. A passivação com $\mathrm{H}_{2} \mathrm{SO}_{4}$ é eficiente, quando comparado ao aço não passivado até concentração abaixo de 1,20 mol. L ${ }^{-1} \mathrm{HCl}$ (limite de resistência).

\section{Agradecimentos}

\section{A Fundação João Ramalho / FASB}

\footnotetext{
${ }^{1}$ Gentil, V. Corrosão, LTC - 6 Edição - (2006).

2 Callister, W. D., Ciência e Engenharia de Materiais: Uma introdução. John Wiley \& Sons, Inc., 2002.

${ }^{3}$ Schmuki, P. From Bacon to barriers: a review on the passivity of metals and alloys. Journal of Solid State Electrochemistry, v.6, p. 145-164, 2002.

${ }^{4}$ ASTM $967-05$

${ }^{5}$ Santos, L. Estudo da decapagem da superfície do aço através da imersão ácida. Revista Científica Semana Acadêmica. Fortaleza, n.85, v.1.

${ }^{6}$ Marques, M. M., et al. Avaliação da passivação dos aços AISI 430 e AISI 439 com dicromato de potássio e ácido nítrico. In: CONIC, $15^{\circ} .2015$.

${ }^{7}$ Viezzer, L. F., et al. Efeito da decapagem química na passivação do aço AISI 439 com solução de ácido nítrico. In: CONIC, 17². 2017.
} 